\title{
THE USE OF KETOPROFEN NIOSOMES FOR FORMULATION OF SUSTAINED RELEASE TABLET DOSAGE FORM
}

\author{
Mohamed A. Raslan, Abd-Elaziz E. Abd-Elaziz, Ahmed M. Samy, Elsherbiny A. Elabd \\ Department of Pharmaceutics and Industrial Pharmacy, Faculty of Pharmacy, Al-Azhar \\ University, Nasr City, Cairo.
}

\begin{abstract}
The objective of this study was to formulate sustained release tablet dosage form (100 mg) using Ketoprofen Niosomes. Ketoprofen Niosomes were prepared by lipid hydration method and then dried and compressed into sustained release tablets (100 mg). The tablet excipients employed include: Avicel PH 101, Avicel PH 102, and Mannitol as diluents, Cab-O-Sil (colloidal silica) as a glidant, Starch as a disintegrant and Magnesium Stearate as lubricating agent. The tablets were tested for weight variation, hardness, friability, thickness, disintegration, drug content and release ratio. Finally the release kinetics of Ketoprofen tablets were calculated.
\end{abstract}

Key words: Ketoprofen; Niosomes; lipid hydration method; sustained release tablets, direct compression

\section{INTRODUCTION}

Development of oral sustained release drug delivery systems is of much interest to the pharmaceutical scientists as these systems provide prolonged duration of action of drugs having short biological half-life, and reduce dose-related toxicity, dosing frequency, and patient non-compliance (Chien, 1997; Uhrich et al., 1999). Among the various sustained release drug delivery systems, pharmaceutical industries prefer sustained release tablet dosage form because of the ease of production using the existing tablet manufacturing infrastructure (Bayomi et al., 2001; Giunchedi et al., 2000; Liew et al., 2006). Various drug delivery techniques have been developed to sustain the release of drugs; recently colloidal particulate carriers such as Niosomes have been employed in drug delivery systems (Shahiwala and Misra, 2002). Due to their capability to carry a variety of drugs, Niosomes has been extensively used in various drug delivery systems like controlled release (Gupta $\boldsymbol{e t}$ al., 2005; Puglia et al., 2004). Sustained release action of Niosomes can be applied to drugs with low therapeutic index and low water solubility since those could be maintained in the circulation via Niosomal encapsulation (Jain et al., 2006). Ketoprofen has some disadvantages as the short half-life, low bioavailability and disturbance in the GI tract, so formulation of controlled release dosage forms is needed (Palmieri et al., 2002).

\section{MATERIALS AND METHODS}

\subsection{Materials}

Ketoprofen was kindly provided by El-Amyria Drug Company, Cairo, (Egypt), Span 60 from Sigma Chemical Co., Steinheim (Germany), Tween surfactants (20, 40, 60, and 80) from El-Nasr pharmaceutical Chemical Co., Cairo, (Egypt), Cholesterol from Sigma Chemical Co., St. Louis, MO, (USA), Sodium hydroxide and Potassium dihydrogen phosphate form El-Nasr Pharmaceutical Chemical Co., Cairo, (Egypt), Chloroform from Labscan Ltd, Dublin, (Ireland), Microcrystalline cellulose (Avicel® ${ }^{\circledR} \mathrm{pH} 101$ and Avicel® ${ }^{\circledR} \mathrm{pH}$ 102 ) from Morgan chemical Ind. Co., Cairo, (Egypt), Amorphous fumed silica (Cab-O-Sil ${ }^{\circledR}$ M-5P), Cabot Corporation, North America, (USA), Magnesium Stearate, Prolabo (France), 
Starch BP 68 from EL Nasr Pharm. Chem. Co., Cairo (Egypt), Mannitol from Sigma Chemical Co., St. Louis, MO, (USA)

\subsection{Equipment}

An electric balance (Mettler AJ100, Switzerland), Ultraviolet spectrophotometer (Jenway 6305 uv/vis, UK), Buchi rotavapor (R-3000, Switzerland), Magnetic stirrer (Type MMS, Germany), Probe Sonicator (Model 275T, Crest Ultrasonic Corp, New York, USA), Dissolution apparatus (Erweka TD6R, Germany), Shaker water bath (Julabo SW-20 C, Germany), Centrifuge (Biofuge, primo Heraeus, Germany), JEOL Transmission Electron Microscope (JTEM model 1010, Japan), Single Punch tablet press, (Royal Artist, Andheri (E), Bombay-400093, India), Tablet Hardness tester (Pharma test, Type PTB 301, Hainburg, Germany), Friability tester, (Pharma test, Type PTF1, Hainburg, Germany), Micrometer (M\&W. Ltd, Sheffild, England), and Disintegration tester (Pharma test, Type PTZ3, Hainburg, Germany).

\subsection{Methods}

\subsubsection{Preparation of Ketoprofen Niosomes}

Ketoprofen Niosomes was prepared by lipid hydration method. The lipid mixture (30 $\%)$ of mixed surfactants (1:1 ratio of Span 60 with Tween 80$)$ and cholesterol (1.5:1 ratio of mixed surfactants to cholesterol) were dissolved in $15 \mathrm{ml}$ of chloroform. The solvent was evaporated using a rotary flash evaporator at speed $(120 \mathrm{rpm})$, under low pressure at $60^{\circ} \mathrm{C}$, which is above the gel-liquid transition temperature $\left(\mathrm{T}^{\circ} \mathrm{c}\right)$ of Span surfactants (Abbas $\boldsymbol{e t}$ al., 2007; Azeem et al., 2008). Niosomes were formed by adding phosphate buffered solution, PBS ( $\mathrm{pH} 7.4$ ) containing $2.5 \%$ concentration of Ketoprofen slowly to the dried thin film formed on the walls of the round-bottom flask, with gentle agitation. The resulting Niosomal suspension was sonicated (Ning et al., 2005; Tejas et al., 2002; Hao et al., 2002) using a probe sonicator, $20-\mathrm{kHz}$, and $500-\mathrm{W}$ vibra cell at 1-min intervals for a period of $15 \mathrm{~min}$.

\subsubsection{Ketoprofen entrapment efficiency}

The non-encapsulated Ketoprofen was separated from the Niosomal dispersions by centrifugation of the dispersion at $15,000 \mathrm{rpm}$ for $45 \mathrm{~min}$ (Jaleh et al., 2003). The supernatant was separated, diluted to $100 \mathrm{ml}$ with PBS pH 7.4, filtered using a membrane filter $(0.2 \mu \mathrm{m}$ pore size), and measured using a spectrophotometer at $262 \mathrm{~nm}$ (Ibrahim et al., 2005). The entrapment efficiency of Ketoprofen ( $\mathrm{EE}(\%)$ ) was calculated by the following equation: $\mathrm{EE} \%=\left[\left(\mathrm{C}_{\mathrm{t}}-\mathrm{C}_{\mathrm{r}} \mid \mathrm{C}_{\mathrm{t}}\right)\right] \times 100 \%$ where $\mathrm{C}_{\mathrm{t}}$ is the concentration of total Ketoprofen and $\mathrm{C}_{\mathrm{r}}$ is the concentration of free Ketoprofen.

\subsubsection{In-vitro release of Ketoprofen}

This study was carried out using a USP dissolution tester (Apparatus I). After separation of the un-entrapped and adsorbed drug, the Ketoprofen Niosomal suspension $(5 \mathrm{ml})$ was placed in cylindrical tubes $(2.5 \mathrm{~cm}$ in diameter and $6 \mathrm{~cm}$ in length). Each tube is tightly covered with a Spectra por@ molecular porous membrane tubing from one end and attached to the shafts of the USP Dissolution tester apparatus, instead of the baskets, from the other end (El-Laithy et al., 2011). The shafts were then lowered to the vessels of the dissolution apparatus containing $250 \mathrm{ml}$ of phosphate buffer ( $\mathrm{pH}$ 7.4) so that the dissolution medium outside and the vesicles preparation inside were adjusted at the same level. The release study was carried out at $37 \pm 0.5^{\circ} \mathrm{C}$, and the stirring shafts were rotated at a speed of $50 \mathrm{rpm}$. Five milliliter samples were withdrawn periodically at predetermined time intervals of $1,2,3,4,6,8,10$, and finally $12 \mathrm{~h}$. Every withdrawal was followed by replacement with fresh medium to maintain a constant volume. The samples were analyzed spectrophotometrically at $262 \mathrm{~nm}$ and the results were the mean values of three runs each representing one batch. The obtained release data were subjected to kinetic treatment according to zero, first, Higuchi diffusion models (Higuchi, 1963), Hixson-Crowell cup root law (Hixson and Crowell, 1977) and Baker-Lonsdale equation (Baker and Lonsdale, 
1974). The correlation coefficient $(r)$, the order of release pattern and $t 50 \%$ value was determined in each case.

\subsubsection{Transmission electron microscopy (TEM)}

A sample drop was diluted 10-fold using de-ionized water and a drop of this diluted dispersion was applied to a collodion-coated 300 mesh copper grid and left for 5 min to allow some of the Niosomes to adhere to collodion. The remaining dispersion was removed by adsorbing the drop with the corner of a piece of filter paper. A drop of $2 \%$ aqueous solution of uranyl acetate was applied for $1 \mathrm{~min}$. The remaining solution was then removed and the sample was air dried and examined with a transmission electron microscope.

\subsubsection{Preparation of Ketoprofen tablets}

The resultant dried sediment of the prepare Ketoprofen Niosomes which is equivalent to $100 \mathrm{mg}$ of Ketoprofen (about $175 \mathrm{mg}$ ) after separation of un-entrapped drug (by centrifugation at 15000 for $45 \mathrm{~min}$ ) was mixed with $325 \mathrm{mg}$ of excipients; Starch was used as disintegrant in two different concentrations (5 and 15\%), Avicel (PH 101), Avicel (PH 102), and Mannitol were used as diluents, Cab-O-Sil (0.5\%) as a glidant, and Magnesium Stearate $(1 \%)$ as a lubricant. Each formula ingredient was sieved through a 20 -mesh size sieve, directly compressed into tablets using the single punch tablet press with flat-faced single punch. The machine was set with hardness of about $5 \mathrm{Kg} / \mathrm{cm} 2$ using flat punch $12 \mathrm{~mm}$ in diameter and had an average weight of about $500 \mathrm{mg}$. Six formulae as illustrated in table (1) were obtained.

Table (1): Composition of the suggested Ketoprofen formulations

\begin{tabular}{|c|c|c|c|c|c|c|}
\hline Components (mg) & F1 & F2 & F3 & F4 & F5 & F6 \\
\hline $\begin{array}{c}\text { Dried Niosomes } \\
\text { (Equivalent to 100 mg } \\
\text { Ketoprofen) }\end{array}$ & 175 & 175 & 175 & 175 & 175 & 175 \\
\hline Mannitol & - & - & - & - & 292.5 & 242.5 \\
\hline Avicel PH 101 & 292.5 & 242.5 & - & - & - & - \\
\hline Avicel PH 102 & - & - & 292.5 & 242.5 & - & - \\
\hline Cab-o-sil & 2.5 & 2.5 & 2.5 & 2.5 & 2.5 & 2.5 \\
\hline Starch & 25 & 75 & 25 & 75 & 25 & 75 \\
\hline Magnesium Stearate & 5 & 5 & 5 & 5 & 5 & 5 \\
\hline
\end{tabular}

\subsubsection{Physicochemical characterization of Ketoprofen tablets}

Characterization of tablets was carried out according to the following parameters: mean weight, thickness, hardness, friability, drug content, disintegration time and dissolution test. Mean weight was determined according to the British pharmacopoeia (B.P.), (2007) (number of tablet $(\mathrm{n})=20$ ). Thickness was determined according to the B.P. (2007) using micrometer $(\mathrm{n}=20)$. Hardness and friability were carried out according to B.P. (2007) using a Pharma test hardness tester and Roche type friability $(\mathrm{n}=20)$. Disintegration was carried out according to the B.P. (2007) using Pharma test disintegration tester $(\mathrm{n}=10)$. Drug content was determined according to the B.P. (2007) $(\mathrm{n}=10)$.

For the dissolution test, seven tablets from each formulation were used. The dissolution test was performed using the USP II basket method. Seven individual tablets from each formula were tested, each tablet was placed in basket, and the basket was rotated at $100 \mathrm{rpm}$ in $250 \mathrm{ml}$ of phosphate buffer $\mathrm{pH} 7.4$ (Jan et al., 2011), and the temperature of the dissolution medium was maintained at $37^{\circ} \mathrm{C} \pm 0.5^{\circ} \mathrm{C}$. Samples of $5 \mathrm{ml}$ were withdrawn at regular time intervals $1,2,3,4,5,6,8,10$ and 12 hours and replaced with an equal 
volume of dissolution medium, filtered, and analyzed spectrophotometrically at $262 \mathrm{~nm}$. The in-vitro release experiments were repeated in triplicate. Release kinetics of drug from all the tablets was also calculated.

\section{RESULTS AND DISCUSSION}

\subsection{Characterization of the prepared formula of Ketoprofen Niosomes}

The entrapment efficiency of the prepared formula was found to be equal $47.20 \pm 0.42 \%$. The cumulative percent release of Ketoprofen from the prepared formula after one hour was $28.89 \%$, after six hours was $71.64 \%$ and after twelve hours was $87.37 \%$. The Kinetic models of the prepared formula were found to obey Higushi's diffusion model.

Transmission electron micrographs revealed the formation of well identified Niosomal vesicles as shown in figure (1). The examined Niosomes appeared as spherical unilamellar nano vesicles with sharp boundaries. Particle size analysis of the optimized formula shows that the size range lied between 162.32 and $288.14 \mathrm{~nm}$ (mean $r \backslash$ I $r \mathrm{rmm}$ )

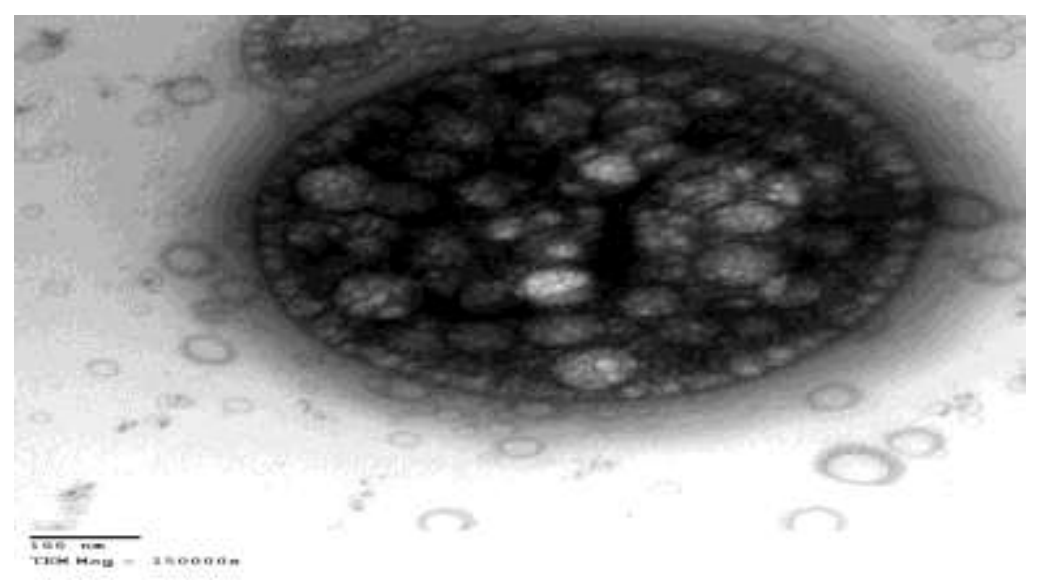

Fig.1. Transmission electron micrograph of the prepared formula

\subsection{Physicochemical characterization of Ketoprofen tablets}

As summarized in table (2); all the investigated Ketoprofen tablets showing that all formulations are within B.P (2007) limits.

Table (2): Physicochemical characterization of Ketoprofen tablets

\begin{tabular}{|c|c|c|c|c|c|c|}
\hline $\begin{array}{c}\text { Physicochemical } \\
\text { characterization }\end{array}$ & F1 & F2 & F3 & F4 & F5 & F6 \\
\hline Weight (gm) & $0.4994 \pm 1.54$ & $0.4998 \pm 1.01$ & $0.4976 \pm$ & $0.4986 \pm 1.62$ & $0.494 \pm 0.73$ & $0.493 \pm 2.13$ \\
\hline Thickness (mm) & $3.444 \pm 0.05$ & $3.622 \pm 0.10$ & $3.532 \pm 0.13$ & $3.526 \pm 0.09$ & $3.660 \pm 0.13$ & $3.872 \pm 0.07$ \\
\hline Hardness (Kg) & $8.13 \pm 0.82$ & $8.47 \pm 0.39$ & $8.854 \pm 0.99$ & $8.912 \pm 0.71$ & $6.43 \pm 0.35$ & $6.72 \pm 0.37$ \\
\hline Friability (\%) & $0.0148 \pm 0.32$ & $0.0133 \pm 0.74$ & $0.009 \pm 0.51$ & $0.008 \pm 0.55$ & $0.019 \pm 0.78$ & $0.01914 \pm 0.95$ \\
\hline $\begin{array}{c}\text { Disintegration } \\
\text { time (min) }\end{array}$ & $7.4 \pm 1.78$ & $8.4 \pm 1.48$ & $9.6 \pm 1.54$ & $10 \pm 1.58$ & $12.2 \pm 1.92$ & $13.4 \pm 1.76$ \\
\hline Drug content (\%) & $98.856 \pm 2.96$ & $98.098 \pm 2.08$ & $96.372 \pm 1.17$ & $97.012 \pm 1.13$ & $95.738 \pm 2.07$ & $95.63 \pm 1.55$ \\
\hline Release (12hr) & $86.94 \pm 1.20$ & $91.81 \pm 0.99$ & $73.8 \pm 0.84$ & $76.92 \pm 0.87$ & $80.45 \pm 1.11$ & $84.37 \pm 1.02$ \\
\hline
\end{tabular}




\subsubsection{Physical characterization of Ketoprofen tablets}

From table (2), it was obvious that formulations containing Avicel PH 102 (formulations 3 and 4) presented higher hardness compared to those prepared with Avicel PH 101 (formulations 1 and 2). This agreed with Bastos and Rossana (2008) who have reported that blends prepared with Avicel $\mathrm{PH} 101$ demonstrated a lower percentage of compressibility (16-18\%) compared to blends containing Avicel PH 102 (18-21\%). This may be explained also by some authors due to the higher surface area of Avicel PH 102 particles (Pasqualoto et al., 2005; Doelker et al., 1995; Hdenp et al., 1997). This agreed with Rowe et al. (2005) who have reported that particles of Avicel PH 102 have a larger surface area (1.21-1.30 m2.g-1)) compared to the particles of Avicel PH 101 (1.06-1.12 m2.g-1). These previous reports can justify the higher hardness of tablets prepared with Avicel PH 102 than those prepared with Avicel PH 101. On the other hand, regarding the evaluation of the friability of tablets, the present study showed that formulations prepared with Avicel PH102 presented a lower friability, which agrees to the result from hardness previously discussed.

Moreover, formulations containing Avicel (PH 101 and 102) (F1-F4) presented higher hardness compared to those prepared with Mannitol (F5 and F6). Higher hardness corresponding to the interaction between microcrystalline cellulose and colloidal silicon dioxide; microcrystalline cellulose particles are preferentially coated by colloidal silicon dioxide and by showing the great interaction forces between microcrystalline cellulose and colloidal silicon dioxide particles, resulting in increasing the hardness (Bastos and Rossana, 2008).

Formulations containing Avicel (PH 101 and 102) (F1-F4) presented shorter disintegration time compared to those prepared with Mannitol (F5 and F6). Beside the higher hardness and lower friability of Avicel containing formulations, it has disintegration properties producing synergistic effect with starch and hence it has a good effect on the disintegration time. On the other hand, Mannitol has good aqueous solubility, negative heats of solution and good wetting properties, these attributes improve the binding of the tablets and water uptake, thereby decreasing disintegration time (Jashanjit and Rajmeet, 2009).

Furthermore, formulations containing low concentration of Starch (formulations 1, 3, and 5) presented lower hardness, lower friability, and shorter disintegration time compared to those prepared with high concentration of Starch (formulations 2, 4, and 6). This agreed with Narmada et al. (2009) who reported that as the concentration of starch increases, hardness also increases. This was explained by Oyi et al. (2009) who reported that as the more starch is forced into interparticulate spaces thereby increasing the area of contact between the particles leading to formation of additional solid bonds and these confer resistance to tablet fracture and abrasion (increase hardness), thereby bringing about a decrease in friability. This also led to a corresponding reduction in the size of the capillary spaces between the particles (leading to the decrease in the friability). This reduction in capillary spaces led to the reduction in the penetration of water into the tablet to cause bond separation and thus, leading to longer disintegration times.

However, the effect of the type of diluent and concentration of disintegrant were clearly observed in the results of hardness, friability, and disintegration time.

\subsubsection{In vitro release study of Ketoprofen from Ketoprofen tablets}

Figure (2) showed the release profiles of Ketoprofen from Ketoprofen tablets. The release profiles of Ketoprofen from tablets were occurred in two distinct phases (biphasic release processes), an initial phase in which rapid drug leakage was observed and stayed for about 8 hours, followed by slow phase stayed at least for 4 hours. This is an indication that the release of Ketoprofen from the prepared tablets is controlled release. 


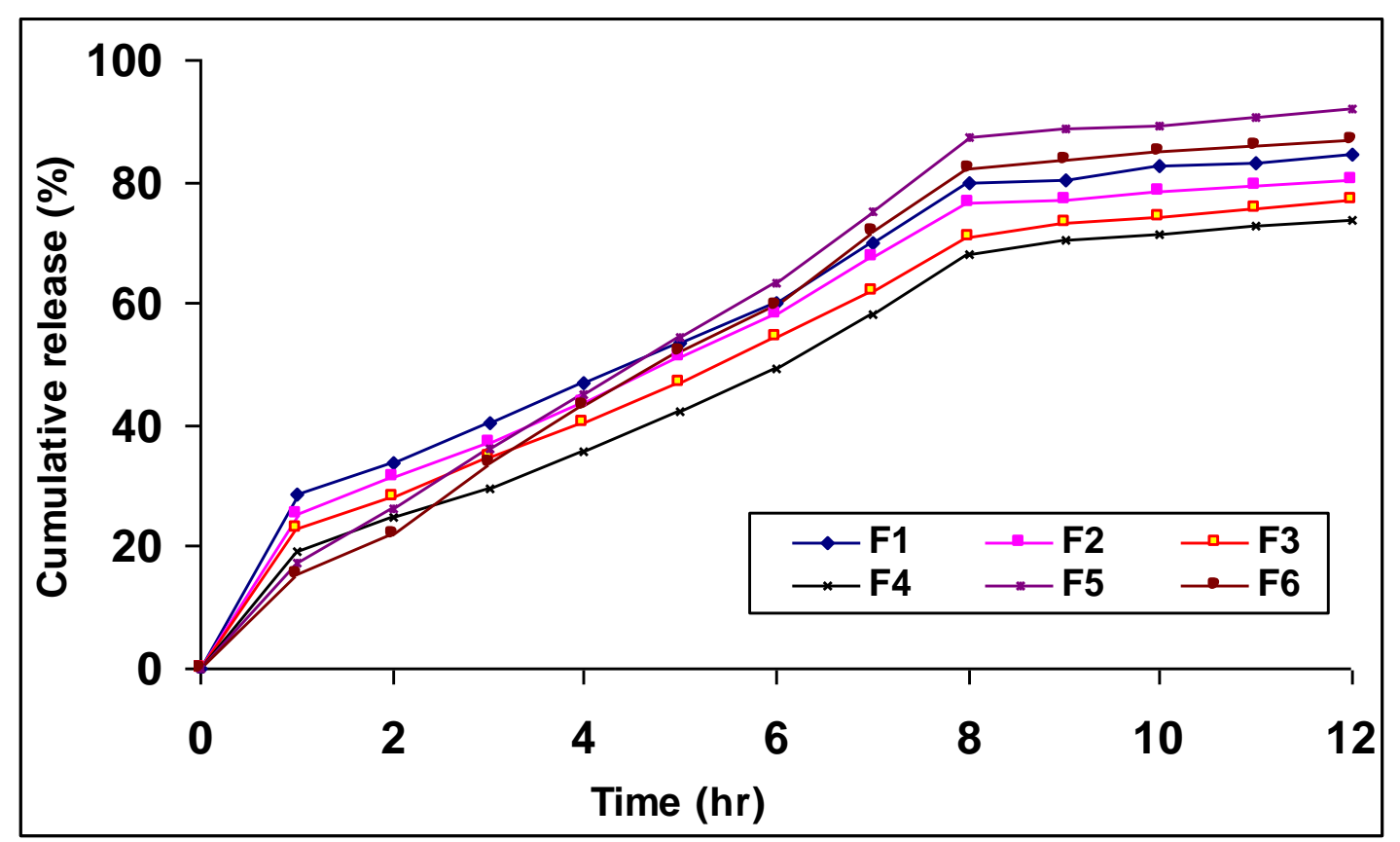

Fig.2. Ketoprofen release profiles from Ketorpofen tablets (F1-F6)

From the in vitro release profiles, we can indicate that, the slow release of Ketoprofen from the prepared tablets ensures that the drug is available for a longer period of time and that too without degradation. The release data indicate that Ketoprofen tables were effective in their release characteristics, as controlled release tablets.

Also from Ketoprofen release profiles, it was obvious that formulations containing Avicel PH 101 (formulations 3 and 4) presented higher release \% compared to those prepared with Avicel PH 102 (formulations 1 and 2). This can be explained by higher hardness corresponding to a higher interaction among the large particles of Avicel PH 102 which could lead to the slow release of Ketoprofen. On the other hand, this result could be related to the lower hardness of tablets prepared with Avicel PH 101. This agreed with Alderborn (2005) who reported that formulations containing Avicel PH 101 presented the highest mean drug release.

Moreover, formulations containing Mannitol (F5 and F6) presented higher release \% compared to those prepared with Avicel (PH 101 and 102) (F1-F4). This can be explained by the higher hardness of Avicel preparations, as the hardness of the tablets is increased the capillary pores are reduced and the penetration of dissolution medium into the tablets is decreased and ultimately there is less dissolution of drugs. This was agreed with Frederic (2010) who reported that the dissolution rate of the drug was decreased as the Avicel was increased. Another explanation may be due to the lower wettability of Avicel. This was agreed with Elsayed et al (2011) who reported that Avicel is insoluble in water; therefore, it may decrease the wettability of Paracetamol and thus decrease its release. On the other hand Mannitol is highly soluble filler so provide the fast rate of drug release (Gaston et al., 2008).

Furthermore, formulations containing low concentration of Starch (formulations 1, 3, and 5) presented higher release $\%$ compared to those prepared with high concentration of Starch (formulations 2, 4, and 6). The decrease in the release \% upon increase in the concentration of starch was explained by Odeku et al. (2006) who have reported that this decrease could be due to its high bond strength and lower swelling capacity which could be responsible for the increase in dissolution time. 
However, the effect of the type of diluent and concentration of disintegrant were clearly observed in the in vitro release results of Ketoprofen.

Table (3) shows the release kinetics of Ketoprofen tablets. The best kinetic order for the in-vitro release of Ketoprofen was calculated from the highest values of the obtained correlation coefficients. The kinetic analysis of all release profiles followed diffusion controlled mechanism with an initial relative fast release phase followed by a slower release one. Similar results were obtained by Kuksal $\boldsymbol{e t}$ al. (2006) who have reported that drug release data of conventional tablet was fitted in first order equation $(\mathrm{r} 2=0.9256)$, while drug release data of batch A and B matrix tablets showed good fit into the Higuchi equation ( $\mathrm{r} 2=$ 0.9837 and 0.9856 , respectively).

Table (3): Kinetic analysis of the release data of Ketoprofen from different prepared tablets

\begin{tabular}{|c|c|c|c|c|c|}
\hline F. No & Model & $\mathbf{R}$ & $\mathbf{K}$ & $\mathbf{t}_{1 / 2}$ & Order \\
\hline \multirow{6}{*}{ F1 } & Zero-order & $\cdot 9 \vee \leqslant$ & $0.7 \times 9$ & $\Lambda . \wedge \wedge r$ & \multirow{6}{*}{$\begin{array}{c}\text { Diffusion } \\
\text { model }\end{array}$} \\
\hline & First-order & .911 &. .101 & 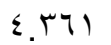 & \\
\hline & Second-order & .979 &.$\ldots$ & $1.9 r r$ & \\
\hline & Higuchi's diffusion model & $.9 \Delta r$ & זч.r. & זrד r. & \\
\hline & H-C & $\overline{.911}$ &. $.1 \mathrm{VI}$ & 0.011 & \\
\hline & B-L & $\cdot 9 \times 7$ & $\because \cdot r_{1}$ & $r .0 . \varepsilon$ & \\
\hline \multirow{6}{*}{ F2 } & Zero-order & $.9 \vee \cdot$ & $0.01 \mathrm{~V}$ & 9.74 & \multirow{6}{*}{$\begin{array}{c}\text { Diffusion } \\
\text { model }\end{array}$} \\
\hline & First-order & $\cdot 9 \vee 9$ & $.1 \% 9$ & $\varepsilon .091$ & \\
\hline & Second-order & $.9 \vee r$ &..$\mu$ & $r .011$ & \\
\hline & Higuchi's diffusion model & $.9 \Lambda Y$ & ro.VqT & r.vov & \\
\hline & H-C & $\overline{.9 \vee \wedge}$ & .107 & $7.1 \cdot v$ & \\
\hline & B-L & $\cdot 9 \times 0$ &. .19 & 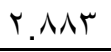 & \\
\hline \multirow{6}{*}{$\mathbf{F 3}$} & Zero-order & 0.977 & 5.383 & 9.287 & \multirow{6}{*}{$\begin{array}{c}\text { Diffusion } \\
\text { model }\end{array}$} \\
\hline & First-order & 0.985 & 0.123 & 5.593 & \\
\hline & Second-order & 0.979 & 0.003 & 3.199 & \\
\hline & Higuchi's diffusion model & $\underline{0.986}$ & 25.074 & 3.976 & \\
\hline & H-C & $\overline{0.984}$ & 0.143 & 6.654 & \\
\hline & B-L & 0.981 & 0.016 & 3.313 & \\
\hline \multirow{6}{*}{ F4 } & Zero-order & 0.976 & 5.549 & 9.009 & \multirow{6}{*}{$\begin{array}{c}\text { Diffusion } \\
\text { model }\end{array}$} \\
\hline & First-order & 0.980 & 0.118 & 5.866 & \\
\hline & Second-order & 0.973 & 0.002 & 3.664 & \\
\hline & Higuchi's diffusion model & $\underline{0.981}$ & 25.747 & 3.770 & \\
\hline & H-C & $\overline{0.980}$ & 0.140 & 6.792 & \\
\hline & B-L & 0.973 & 0.015 & 3.609 & \\
\hline \multirow{6}{*}{ F5 } & Zero-order & 0.967 & 7.322 & 6.872 & \multirow{6}{*}{$\begin{array}{c}\text { Diffusion } \\
\text { model }\end{array}$} \\
\hline & First-order & 0.977 & 0.239 & 2.895 & \\
\hline & Second-order & 0.951 & 0.010 & 0.919 & \\
\hline & Higuchi's diffusion model & $\underline{0.983}$ & 34.391 & 2.113 & \\
\hline & H-C & $\overline{0.979}$ & 0.240 & 3.974 & \\
\hline & B-L & 0.969 & 0.031 & 1.739 & \\
\hline \multirow{6}{*}{ F6 } & Zero-order & 0.966 & 7.053 & 7.089 & \multirow{6}{*}{$\begin{array}{c}\text { Diffusion } \\
\text { model }\end{array}$} \\
\hline & First-order & 0.980 & 0.194 & 3.561 & \\
\hline & Second-order & 0.965 & 0.006 & 1.491 & \\
\hline & Higuchi's diffusion model & $\underline{0.984}$ & 33.170 & 2.272 & \\
\hline & H-C & 0.980 & 0.209 & 4.566 & \\
\hline & B-L & 0.973 & 0.025 & 2.116 & \\
\hline
\end{tabular}




\section{CONCLUSION}

The overall results of this study showed that Ketoprofen tables were effective in their release characteristics, as sustained release tablets. However, the effect of the type of diluent and concentration of disintegrant were clearly observed. Avicel PH 101 and $5 \%$ concentration of starch (lower concentration) gave the best effect on the Ketoprofen tablets.

\section{REFERENCES}

Abbas, P., Jaleh, V., and Abdolhossein, R., (2007): In vitro study of polyoxyethylene alkyl ether niosomes for delivery of insulin, Int. J. Pharm., 328, 130-141.

Alderborn, G., (2005): "Comprimidos e compressão", en "Delineamento de Formas Farmacêuticas", (M. E. Aulton, ed.), Artmed, Porto Alegre, 401-43.

Azeem, A., Ahmad, F.J., Khan, Z.I., and Talegaonkar, S., (2008): Nonionic surfactant vesicles as a carrier for transdermal delivery of frusemide, J. Dispers. Sci. Technol., 29, 723-730.

Baker, R.W., and Lonsdal, H.K., (1974): in "Controlled Release of Biologically Active Agents", Tanquary, A.C. and Lacey, R.E., (Eds.), Plenum Press, New York, p.15.

Bayomi, M.A., Al-Suwayeh, S.A., and El-Heiw, A.M., (2001): Excipient-excipient interaction in the design of sustained-release theophylline tablets: In vitro and in vivo evaluation. Drug Development and Industrial Pharmacy, 27 (6), 499506.

Bastos, M.D., and Rossana B.F., (2008): Effects of Filler-Binders and Lubricants on Physicochemical Properties of Tablets Obtained by Direct Compression, Lat. Am. J. Pharm., 27 (4), 578-83.

British Pharmacopoeia, (2007): Her Majesy's Stationary Office, London.

Chien, Y.W., (1997): In Chien, Y.W., (Ed.), Novel drug delivery system (2nd ed., pp. (142). New York: Marcel Dekker Inc.

Doelker, E., Massuelle, D., Veuillez, F., and Humbert-Droz, P., (1995): Drug Dev. Ind. Pharm., 21, 643-61.

El-Laithy, H.N., and Shoukry, O., and Mahran, L.G., (2011): Novel sugar esters proniosomes for transdermal delivery of vinpocetine: Preclinical and clinical studies, Int. J. Pharm., 77, 43-55.

Elsayed, A., Al-Badawi, A., Al-Khatim, A., and Mohammed, K., (2011): Investigation of the effects of certain formulation factors on release properties of paracetamol tablets using 23 factorial design, Sudan JMS, 6 (2), 11-13.

Frederic, O.Y., Kwabena, O.K., and Samuel L.K., (2010): Formulation and quality evaluation of two conventional release tablet formulations, Int. J. of Pharm. Sic., 4 (1), 76.

Gupta, P.N., Mishra, V., Singh, P., Rawat, A., Dubey, P., Mahor, S., and Vyas, S.P., (2005): Tetanus toxoid loaded transfersomes for topical immunization, J. Pharm.Pharmacol., 57, 295-301. 
Giunchedi, P., Gavini, E., Moretti, M.D.I., and Pirisino, G., (2000): Evaluation of alginate compressed matrixes as prolonged drug delivery systems. AAPS Pharm. Sci. Tech., 1(3), 31-36.

Hao, Y., Zhao, F., Li, N., Yang, Y. and Li, K., (2002): Studies on a high encapsulation of colchicine by a noisome system, Int. J. Pharm., 244: 73-80.

Hdenp, L., Niskanen, M., and Yliruusi, J., (1997): Eur. J. Pharm. Biopharm., 43, 315-22.

Higuchi, T., (1963): Mechanism of sustained-action medication: theoretical analysis of rate of release of solid drugs dispersed in solid matrices, J. Pharm. Sci., 52, 11451148 .

Hixson, A.W., and Crowel, G.H., (1977): in 'pharmaceutics of solid dosage forms", Willy, New York.

Ibrahim A., Bosela, A.A., Ahmed, S.M., and Mahrous, G.M., (2005): Proniosomes as a drug carrier for transdermal delivery of ketorolac, European J. Pharm. Bioph., $59,485-490$.

Jain, N.K., Ramteke, R.B., and Maheshwari, U.A., (2006): Clarithromycin based oral sustained release nanoparticulate drug delivery stystem. Indian J. Pharm. Sci. 68 (4), 479.

Jaleh, V., Pardakhty, A., and Hajhashemi, V., (2003): Development and Physical Characterization of Sorbitan Monoester Niosomes for Insulin Oral Delivery, Drug Deliv., 10, 251-262.

Jan, S.U., Khan, G.M., Khan, K.A., Rehman, A.U., and Khan, H., (2011): In-vitro release pattern of ketoprofen using ethyl cellulose Ether derivatives, J. App. Pharm., $1(03), 149-158$.

Jashanjit, S., and Rajmeet, S., (2009): Optimization and Formulation of Orodispersible Tablets of Meloxicam, Tro J. of Pharm. Res., 8 (2), 153-159.

Kuksal, A.K., Narendra, T., Jain, K., and Jain, S., (2006): Formulation and In vitro, in vivo evaluation of extended- release matrix tablet of Zidovudine: influence of combination of hydrophilic and hydrophobic matrix formers, AAPS Pharm. Sci. Tech., 7 (1), 1-3.

Liew, C.V., Chan, L.W., Ching, A.L., and Heng, P.W.S., (2006): Evaluation of sodium alginate as drug release modifier in matrix tablets. In. J. Of Pharm., 309, $25-37$.

Modi, S.A., (2011): Sustained release drug delivery system: a review, In. J. of Pharm. Res. And dev., 2, 12.

Narmada, G., Mohini, K., Prakash R., Gowrinath, D., and kumar K., (2009): Formulation, Evaluation and Optimization of Fast Dissolving Tablets Containing Amlodipine Besylate by Sublimation Method, Ars Pharm, 50 (30), 129-144.

Ning, M., Gu, Z., Pan, H., Yu, H., and Xiao, K., (2005): Preparation and in vitro evaluation of liposomal/niosomal delivery systems for antifungal drug clotrimazole, Indian J. Exp. Biol., 43 (2),150-7.

Odeku, O.A., and Itiola, O.A., (2006): Tablet Evaluation Tests. In: Free Books. Retrieved from http://www.Pharminfo.net.

Oyi, A.R., Allagh, T.S., and Olayemi, O.J., (2009): Comparative Binding Effects of Wheat, 
Rice and Maize Starches in Chloroquine Phosphate Tablet Formulations, Res. J. of App. Sci., 1(2), 77-80.

Palmieri, G.F., Bonacucina, G., Di Martino, P., and Martelli, S., (2002): Microencapsulation of semisolid ketoprofen/polymer microspheres, Int. J. Pharm, 242 175-178.

Pasqualoto, K.F.M., Funck, J.A.B., Silva, F.E.B., and Kratz, C.P., (2005): Acta Farm. Bonaerense, 24, 39-47.

Puglia C., Trombetta D., Venuti V., Saija A., and Bonina F., (2004): Evaluation of in vivo topical anti-inflammatory activity of indometacin from niosomal vesicles, J. Pharm. Pharmacol., 56, 1225-1232.

Sayed, I., Abdel-Rahman, S., Gamal, M.M., and El-Badry, M., (2009): Preparation and Comparative Evaluation Of sustained release metoclopramide hydrochloride matrix tablets, Saudi Pharm. Journal 17, 283-88.

Shahiwala, A., and Misra, A., (2002): Studies in topical application of niosomally entrapped nimesulide. J. Pharm. Sci. 5(3), 220-225 (2002).

Tejas, R., and Desai, W.H., (2002): Finlay Nebulization of niosomal all-trans-retinoic acid: an inexpensive alternative to conventional liposomes, Int. J. Pharm., 241, 311317.

Uhrich, K.E., Cannizzaro, S.M., Langer, R.S., and Shakesheff, K.M. (1999): Polymeric systems for controlled drug release. Chemical Reviews, 99, 3181-3198.

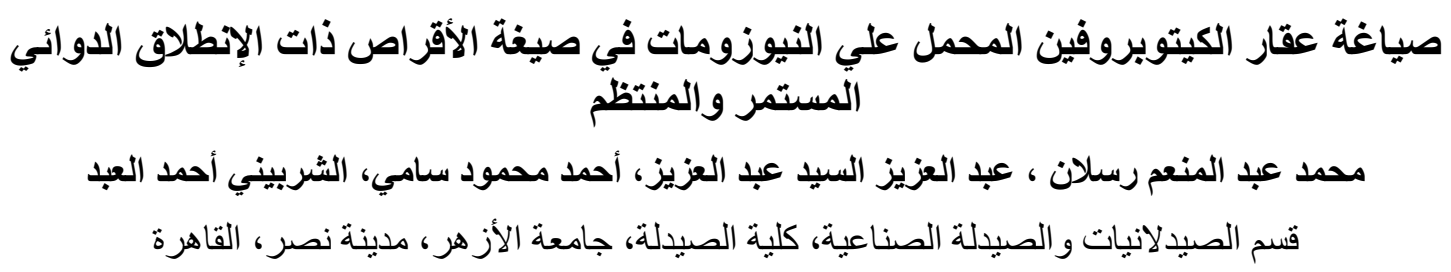

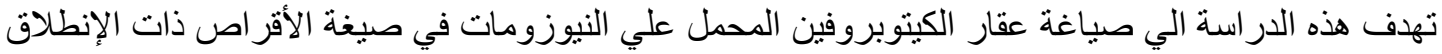

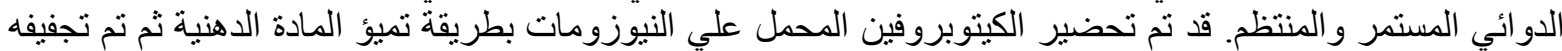

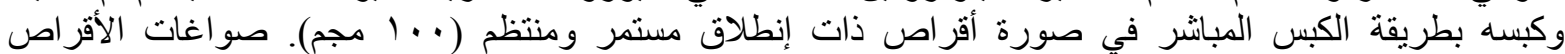

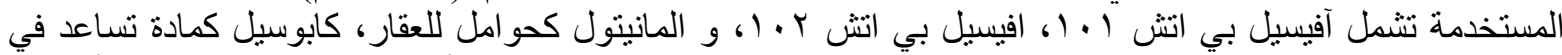

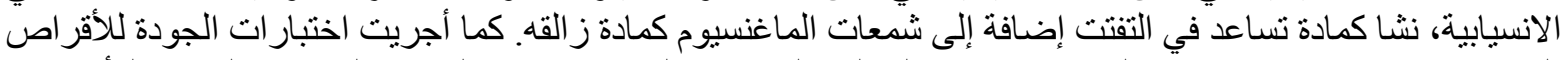

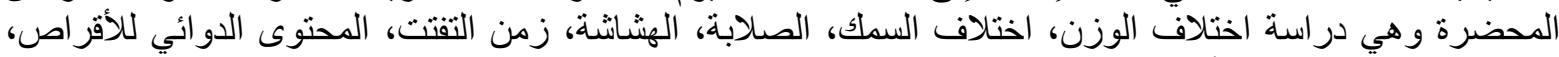
معدل الإنطلاق المعملي. وأخير ا تم تعيين حركية الإنطلاق اللعقار. 
